\title{
Stop Making Sense: The Politics of Aristophanic Madness
}

\author{
IAN A. RUFFELL
}

Vultan: What is this?

Zarkov: Humanity.

Vultan: Madness!

(Flash Gordon $)^{1}$

This paper discusses the use of madness in Aristophanic Comedy, and in particular how it is used as a means of evaluating and interrogating political interventions. The well-known theme of madness in Aristophanes's Wasps provides the frame. Interpreting Philocleon's madness has proved problematic because the complexity of comic madness has been under-estimated. Against negative models of madness that dominate in tragedy and in political discourse, madness in comedy can be not only a means of interrogating ideological and political norms, but also a constructive and even heroic form of behavior, which draws on epic and religious associations. Bdelycleon's attempt to cure his father removes the positive substance and political value that anchors his father's insanity, which leads to the aporetic finale.

In this paper, I explore the connotations of madness in Old Comedy, with a particular interest in their political dimensions. ${ }^{2}$ The obvious starting point for such a study is Aristophanes's Wasps, which consequently bookends the paper. Madness is, however, a running theme in Old Comedy, not least in Aristophanes, and I shall argue that the full range of implications of comic madness have not been fully appreciated and that as a result Wasps has appeared rather more puzzling and problematic than it really should have. The central part of the paper demonstrates how comic madness both exploits and differs from the rhetoric of madness in Athenian politics, and how it engages in a multi-stranded generic dialogue that constructs a rich and productive behavior and affect. Far from

1. Hodges (1980).

2. Aristophanes is quoted from the Oxford Classical Text of Wilson (2007), except where noted. Demosthenes is quoted from the Oxford Classical Text of Butcher (1903-31). All translations are my own. 
straightforwardly negative, comic madness can be successful, positive, or a way of disclosing or rethinking norms and values. Philocleon's madness is certainly the central element in Wasps but it represents not the problem itself, directly; it is only a symptom of a much deeper problem innate in the city.

\section{The Problem}

Wasps is certainly the play where the problem of comic madness can be seen in its most acute form. The play is set up in the prologue in a slave dialogue as an attempt to cure the madness of an old man. With knockabout interaction with the audience, the slaves establish that it is not any regular obsession, such as alcoholism or gambling, but an all too new disease, a compulsion for being

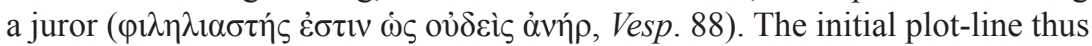
focuses on the efforts of the slaves and their young master, Bdelycleon (LoatheCleon), to cure his father, Philocleon (LoveCleon). ${ }^{3}$

It has long been noted that the language used of Philocleon's condition, particularly the use of nosos, disease, echoes that of tragedy, especially Euripides. ${ }^{4}$ The Phaedra of Euripides's extant Hippolytus is the obvious parallel, but her love passion echoes other transgressive obsessions among Euripides's run of notorious female characters, including Stheneboea and indeed the original Phaedra of Hippolytos kalyptomenos. Attempts to cure Phaedra's disease, either through her own efforts (abstinence or suicide) or through the interference of her nurse, only lead to disaster. Arguably none of the remedies attempted, suggested, or implied in Hippolytus actually seek to cure the underlying problem. The nurse's account of her medicinal resources is a masterpiece of ambiguity and her main approach is to alleviate Phaedra's misery by encouraging her to overcome her inhibitions. ${ }^{5}$

Bdelycleon and his team seem rather more transparent than Phaedra's nurse, but thus far they have been no more successful in addressing their problem, despite trying all manner of orthodox, but fruitless, remedies, both medical and ritual (117-24). After an attempt to argue the case rationally, Bdelycleon

3. The emphasis on this being a disease (nosos) that causes Philocleon to behave irrationally suggests that "madness" would be an appropriate term here. Explicit vocabulary of mental disturbance is introduced after Philocleon's behavior has been summarized, at 111: "That is the way he

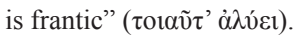

4. Harvey (1971); see also Sidwell (1990) and Wright (2013).

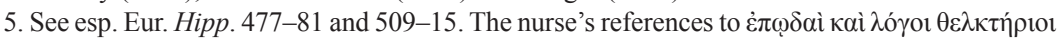

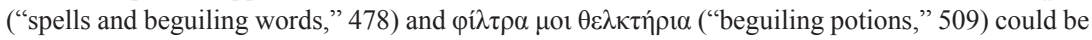
used just as plausibly, if not more so, to potions that cause love rather than to potions that ward it off. So Barrett (1964) 247-48 and 254-55 ("the whole thing is a string of ambiguities"). 
will (rather like the nurse) eventually resort to allowing his patient to indulge his obsession, with the proviso that he exercises his mania for judging solely at home. However we may characterize Bdelycleon's attempts to cure his father, he seems (initially at least) to be acting in good faith.

More recently, it has been noted that both Philocleon's disease and the plot-lines owe more than a little to Cratinus's Pytine, which had beaten Clouds at the immediately preceding festival, the Dionysia of 424/3 B.C.E. That defeat prompted a series of responses from Aristophanes, as explicitly in the parabasis of Wasps and implicitly in the self-criticism of its prologue. Pytine had featured a self-reflexive representation of the comic poet ignoring his wife, Comedy, and running around after young wines and Drunkenness. The description of the alcoholically out-ofcontrol poet (fr. 199) clearly picks up the abuse directed at Cratinus by Aristophanes in Knights (526-36), and there seems to have been an effort to cure Cratinus, with some degree of self-awareness as a result (fr. 200). But whether such an attempt was successful or not is unclear, given the current evidence. It used to be assumed that Cratinus was cured and rejuvenated, largely based on a rather one-eyed view of Wasps and the genre of Old Comedy in general. ${ }^{6}$ More recently, this has been questioned, whether as a one-off response to the charges of Knights or as part of a more consistent rhetoric of alcoholic inspiration. ${ }^{7}$ The dangers of circular argument are evident here, but however it was played in Pytine, the comment that Philocleon's disease is not alcoholism (78-80) is an obvious pointer that the audience should be considering the one comic play in the light of the other. ${ }^{8}$

Whether this is building on or dissenting from Cratinus, it seems that in many important ways Philocleon's madness is only notionally cured, and instead the madness is displaced. The groundwork for this shift takes place in the agon and culminates in the trial of the dog, Labes. In the first place, there is a subtle shift in emphasis from an obsession with going to court to an obsession with convicting. The argument between father and son in the agon over the ideological basis of acting as a juror introduces a presumption of guilt on the part of defendants (554-57). In the second place, Philocleon's resistance to the blandishments of his son is presented more as a matter of character and will, rather than reasoned argument. Unlike the chorus, who accept the force of Bdelycleon's words, Philocleon only gives in to the extent of going along with

6. This view is still to be observed in Luppe (2000) and Rosen (2000).

7. As an ad hoc response: Ruffell (2002); part of a systematic self-representation: Biles (2002) 170-77, (2011) 138-44, largely followed by Bakola (2008), (2010) 16-24, albeit as part of a more complex set of poetic self-representations.

8. So Biles (2002) 189-201, (2011) 154-66, with a full analysis; cf. Ruffell (2002) 162. 
the experiment of a trial at home. ${ }^{9}$ So the domestic trial of the dog, who has conveniently been accused of stealing an allegorical Sicilian cheese, becomes a battle of wills, centered not on going to court as such, but on whether or not Philocleon will convict. Bdelycleon's agenda in the domestic trial is to induce his father to acquit the defendant at all costs. Accordingly, as the contest has shifted from ideology to character, when Philocleon eventually does let off the defendant, he collapses and allows his son to take him in hand:

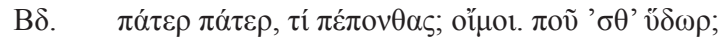

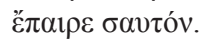

$\Phi 1$.

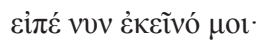

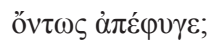

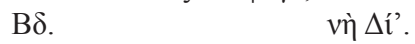

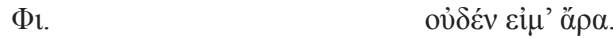

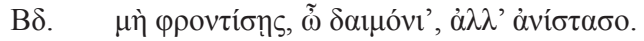

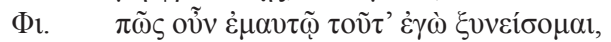

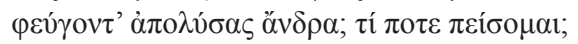

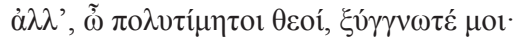

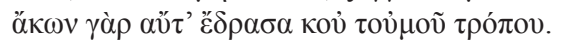

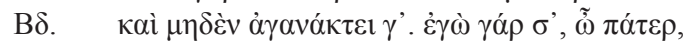

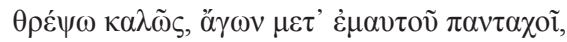

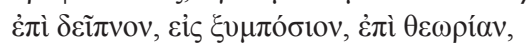

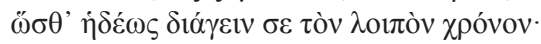

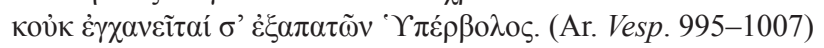

Bd. Father, father, what's wrong? Oh no! Where's some water? Lift yourself up.

$\mathrm{Ph}$. did he really get off?

Bd. Yes, by Zeus.

$\mathrm{Ph}$.

Then I am no more.

Bd. There, there, don't fret. Come on, stand up.

$\mathrm{Ph}$. But how can I live with myself with this knowledge, that I let a defendant off? What will become of me? O highly honored gods, forgive me. I did it unwillingly, and not at all in character.

Bd. Don't take it so hard. For, father, I'll look after you well, taking you with me everywhere,

9. Philocleon weakens at 696-97 and, especially, 713-14, but rallies at 751-59, in contrast to the chorus (725-35). Although Philocleon agrees to the trial at home in the following scene (776), it rapidly diverts into questions of practicality and associated routines. 
to meal, symposium and festival, so that you live your life pleasantly in future:

and Hyperbolos will no longer scoff at deceiving you.

Central to Bdelycleon's arguments hitherto, and as it culminates here, is the idea that his father should have a relaxed and pampered lifestyle rather than constantly going to court. ${ }^{10}$ Pampering in the domestic context, to which Philocleon is resistant, mirrors the argument that Bdelycleon has made about how public revenues are and are not being spent (656-718), just as the domestic court mirrors the public one. As it transpires however, this essentially paternalistic stance ${ }^{11}$ becomes an extended lesson in manners in how to attend the symposium, or a particular type of elite symposium. Although Bdelycleon has broken Philocleon's will, he has not fundamentally altered Philocleon's character, as his response to this re-education already suggests. ${ }^{12}$ Philocleon's excessive behavior in the lawcourt - at least as parsed by Bdelycleon - transfers wholesale to the symposium, from which he makes off with some of the female entertainment (1341-81) and becomes the object of legal claims from injured parties (1332-34, 1338-41).

Finally, in what seems a bizarre ending, he emerges from the house to challenge all-comers to a dancing competition (1484-1503). The only offers to meet the challenge come from a tragic source, the sons of Carcinus, who appropriately enough appear as crabs.

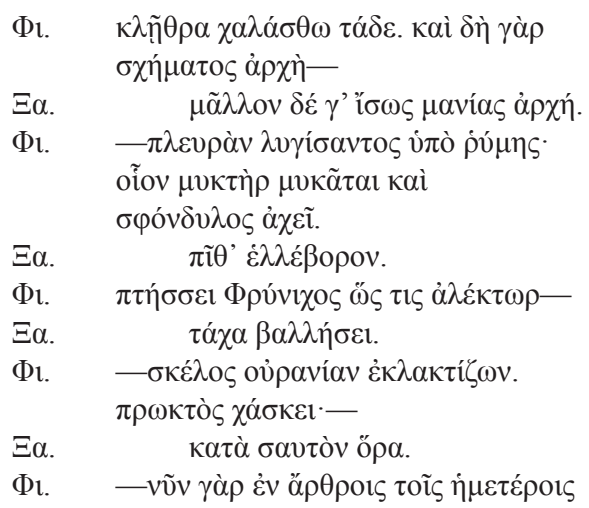

10. See lines 719-24, 736-40, 765-66, 777-78.

11. So, e.g., de Ste. Croix (1972) 357, referring to Aristophanes's political attitude in general; see also de Ste. Croix (1972) 362.

12. Whether that is understood in psychological, behavioral, or thematic terms. This is not to play down arguments that have been made against psychological realism, on different grounds for either tragedy or comedy. The question of motivation in humor remains important even where characters are not realistic and may, as here, be based around a key trait or small set of traits. 


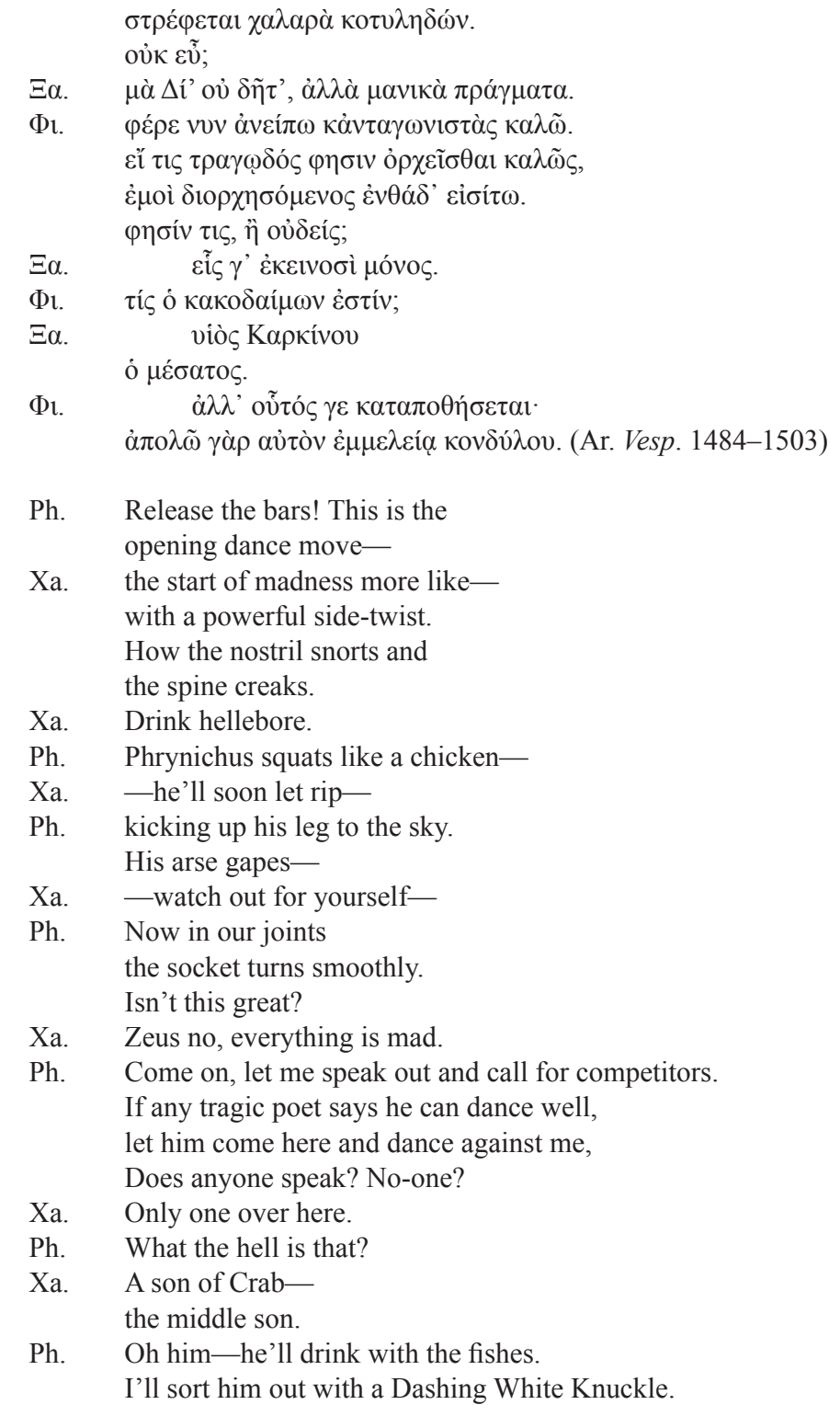

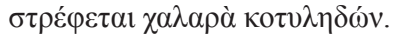

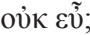

$\Xi \alpha . \quad \mu \alpha \grave{\alpha} \hat{i}^{\prime}$ ov̉ $\delta \tilde{\eta} \tau$ ', $\dot{\alpha} \lambda \lambda \grave{\alpha} \mu \alpha v i \kappa \alpha ̀ ~ \pi \rho \alpha ́ \gamma \mu \alpha \tau \alpha$.

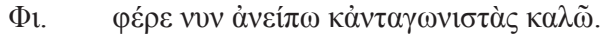

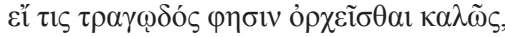

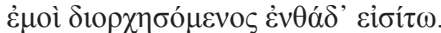

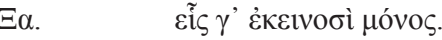

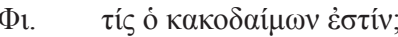
ó $\mu \dot{\varepsilon} \sigma \alpha \tau \sigma \zeta$.

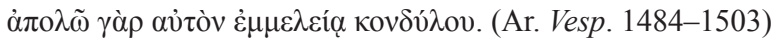

opening dance move-

with a powerful side-twist.

How the nostril snorts and

the spine creaks.

Drink hellebore.

Ph. Phrynichus squats like a chicken-

Xa. - he'll soon let rip-

$\mathrm{Ph}$. kicking up his leg to the sky.

His arse gapes-

Xa. - watch out for yourself-

the socket turns smoothly.

Isn't this great?

Xa. Zeus no, everything is mad

$\mathrm{Ph}$. Come on, let me speak out and call for competitors.

If any tragic poet says he can dance well, et him come here and dance against me,

Does anyone speak? No-one?

Xa. Only one over here.

$\mathrm{Ph}$. What the hell is that?

the middle son.

I'll sort him out with a Dashing White Knuckle.

From the language that the slave, Xanthias, uses to describe him, Philocleon is no saner at this point in the play than he is earlier. He is no more successfully cured than was Phaedra (or, perhaps, Cratinus). 
What then are we to make of the plot of Wasps that seems to end in such a manic aporia, a cure, in effect, that is no cure? How, in particular, does it relate to the shift from the judicial focus of the first two-thirds of the play before the parabasis to the apparently private sphere of the last third of the play? Is the personal no answer to the political? Or do we have to suppose that Philocleon's character is the only thing that matters, in a kind of existential triumph? ${ }^{13}$ One way of approaching these questions is through a close reading of Wasps and a consideration of how the two parts of the play thematically relate. ${ }^{14}$ Another, and the focus of this paper, is through examining what madness means to comedy and the comic audience.

\section{Madness in Old Comedy}

The meaning of madness might seem straightforwardly negative, associated with a lack of logic, with thoughtlessness or even stupidity. That is, indeed, how it is used in law-court and assembly speeches (albeit mainly from the fourth century). Old Comedy clearly draws on and engages with such rhetorical uses of madness, but as I shall show in this section, it has a richer approach to both logic and madness: challenging the former and re-evaluating the latter - in part because of its own generic possibilities, in part drawing on madness in other discourses, such as epic.

Perhaps the most relevant rhetorical context for Wasps, given the domestic setup where the son has displaced the father in control of the household, is the legal invocation of madness in questions of competence to dispose of one's own property, particularly in cases dealing with inheritance. Incompetence, according to the speakers, can arise from age, madness, or being influenced by a woman. ${ }^{15}$ This sort of allegation colors Callistratus's accusations against Olympiodorus, for allegedly acting under the influence of his hetaera:

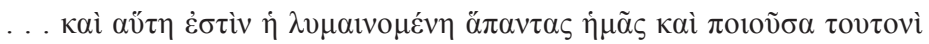

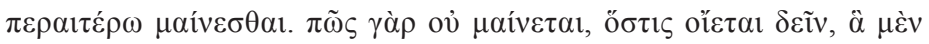
ஸ் ò

13. For the latter, see especially Silk (1987).

14. See especially Vaio (1971); also Ruffell (2011) 127-55.

15. See Isae. 6.9 (On Philoctemon); Dem. 46.14, 16 (Against Stephanus 2). In the first and last of these passages, $\mu \alpha v i$ í is coupled with $\pi \alpha \rho \alpha ́ v o r \alpha$, which is almost exclusively used of questions of competence: see, in addition, Isae. 2.1, 19, 38 (On Menecles); 4.14-16 (On Nicostratus); cf.

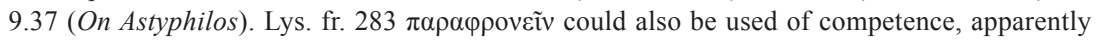
interchangeably: Isae. 2.20, 25, cf. 2.40 (On Menecles); Dem. 48.18, 56 (Against Olympiodorus). 
... she is the one who has been insulting all of us and making him over there even more insane. For how is he not mad, who thinks it unnecessary to do any of what he agreed and freely entered into and swore ...?

Madness is, more generally, something to be imputed to enemies, foreign and domestic, to question their actions, motives, or arguments, ${ }^{16}$ or to third parties who are implicated in disputes, ${ }^{17}$ or ascribed more generally. ${ }^{18}$ As well as direct and indirect allegations in the formal context in which a speech is made, speakers narrate interactions where allegations of madness were thrown about. ${ }^{19}$ But it is perhaps most commonly used counterfactually or hypothetically, as a way of assuring the audience that the competence, motives, and argument of the speakers or their clients are beyond reproach, ${ }^{20}$ or for some other argumentative purpose. ${ }^{21}$ Actual, counterfactual, or potential madness can also be laid at the door of the Athenians themselves, specifically.22 In all such scenarios, madness is unequivocally negative.

It is possible to see echoes of that rhetorical use of madness in Aristophanes. Most literal is the preparation for the assembly in Ecclesiazusae, where Praxagora uses the allegation of madness as a rejoinder to Cephalus, and Aristophanes reinforces the point with the woman's further response.

\begin{tabular}{|c|c|}
\hline$\Gamma v .^{\alpha}$ & 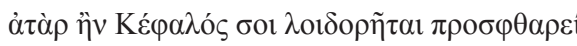 \\
\hline & 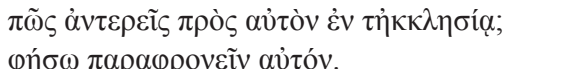 \\
\hline Гv. & 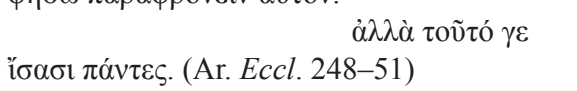 \\
\hline Wo. ${ }^{1}$ & $\begin{array}{l}\text { What if Cephalus gets in first with an insult, } \\
\text { how will you answer him in the assembly? }\end{array}$ \\
\hline Pr. & I'll say that he's off his head. \\
\hline Wo. ${ }^{1}$ & $\begin{array}{l}\text { Yeah, but } \\
\text { everyone knows this. }\end{array}$ \\
\hline
\end{tabular}

Likewise, in another context that evokes democratic political institutions, Euripides's kinsman professes sanity as he opens his notional defense of the poet

16. Isoc. 5.65, 8.108, 141; Isae. 1.20, 34; Lys. 3.7; Dem. 18.249, 19.201, 314, 36.48; Lycurg. Against Leocrates 63; Din. Against Demosthenes 113.

17. Dem. 16.23, 19.260.

18. Especially in Isoc.: $5.88,8.17,12.14,157,26.16$.

19. Isoc. 12.206; Dem. 34.14, 50.35 .

20. Antiph. Tetr. 2.5; Isoc. 8.66, 15.273, 17.47; Lys. 3.29, 21.22; Dem. 18.51, 21.69, 208, Dem. $34.16,35.40,52.11,57.64$.

21. Isoc. 1.15, 8.41, 14.34, 15.90; Lys. 29.7; Dem. 8.25, 9.9, 14.29, 19.95, 138.

22. Aeschin. 3.211. Dem. 24.58; Hyp., For Euxenippus col. 23 Jensen. 
before the women's assembly in Thesmophoriazusae by establishing his credentials and denouncing the tragedian.

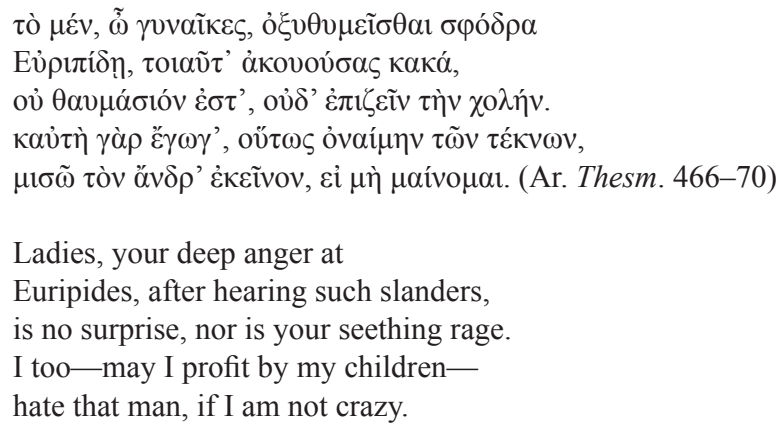

Circumstances are, however, very different in comedy compared with oratory: a lack of logic or rationality, or the upholding of a proportionate response is rarely a disadvantage, particularly at the level of plot. Indeed, part of the joke in the latter passage is that the question of the sanity of Euripides's relative is an open one, given that he has agreed to undertake this undercover mission to defend Euripides to the hostile women's assembly. As Agathon, to whom Euripides had first turned as a more plausible infiltrator, puts it, "I would be mad

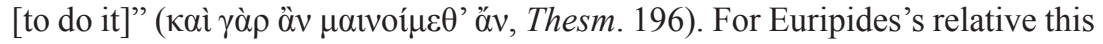
has already led to him being forcibly depilated and cross-dressed, with further humiliation to follow. Given the unusual situation in the play, this may be crazy but it is also set up as necessary.

Such a complex or ambivalent perspective is typical of the handling of madness in Aristophanic comedy. A challenge to reason is made in every surviving play after Knights, and madness becomes increasingly foregrounded where the competing positions are, as in Wasps, strongly contested. It becomes much harder to see where madness truly lies, despite the confident assertion of some characters.

In some of the plays that most closely follow the stereotypical plot of Old Comedy, where the central character has an idea that ranges from the unconventional to the downright impossible, accusations of madness can feature right from the beginning of the play. Thus the set-up of Peace is with a slave conversation about their current activity which is dramaturgically similar to Wasps. ${ }^{23}$ Their conversation is likewise about madness (54-55), but this time the madness belongs to the man with the plan, Trygaeus, who is having them fatten up a dung-

23. It is also structurally similar to Knights as a slave dialogue about a master, but the character of the master there is not the immediate protagonist. 
beetle so that he can ride it to challenge the gods in the manner of Euripides's Bellerophon flying to Olympus on Pegasus (54-68). The tragic background becomes increasingly apparent and overcoded as the children emerge to query their father's actions, parodying Aeolus (114-18, another Euripidean male with even more questionable goals). ${ }^{24}$ The children challenge the credibility or plausibility of Trygaeus's imitation of Bellerophon in this manner (131-35); Bellerophon's lack of success - falling from Pegasus to become one of Euripides's beggar-heroes - is also thematized in the ascent on the dung-beetle (146-48). One of the (ironic) points of the exercise is, of course, that unlike Bellerophon Trygaeus, borrowing his implausible steed from fable, is entirely successful. ${ }^{25}$

Challenges to the central character's plans in terms of madness, similar to those of Peace are made in Wealth and Birds, which both have utopian plots with male protagonists. In Birds, we see a variant on the challenge to the protagonist. Rather than a slave prologue, it is deferred to the point where Tereus (a hoopoe, $\varepsilon \tilde{\pi} \pi \%)$ sells the plan to the chorus of birds. They think that the megalomaniac plan is insane.

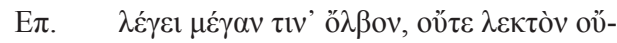

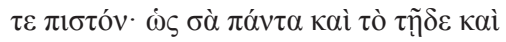

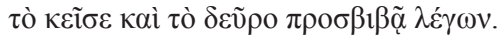

Хo. $\quad \pi$ ó $\varepsilon \rho \alpha \mu \alpha 1 v o ́ \mu \varepsilon v o \varsigma ;$

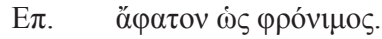

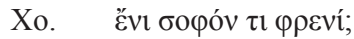

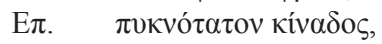
бó

Cho. He talks of some great wealth - indescribable and unbelievable; he makes the attractive case that everything can be yours: here, there, everywhere.

Cho. Is he mad?

Ter. Unspeakably sane.

Cho. Does he have clever thoughts?

Ter. He's a devilish cunning fox:

sophisticated, sneaky, polished, entirely subtle.

Tereus's response is hardly a good character reference, but the rest of the play rather supports his contention that Peisetaerus has the capacity to carry out his plan - however that may be evaluated in the end. 
In Wealth, Cario returns to the slave/master interaction of Wasps and Peace, amplifying it into a general statement of the lot of the slave bound to a delusional master (1-7, esp. 1-2) — but again, as in Peace and Birds the alleged insanity does not preclude success. It is worth observing here that where one might expect more of this language, in Frogs where Xanthias is a famously challenging slave, we do not find such a general attack on his master's sanity, despite the dubious nature of Dionysus's disguise and plan. What we find instead is a specific comeback on a single moment of Dionysus's lack of self-awareness (41), namely amid Heracles's response to his disguise. What Xanthias does do is make the charge of madness direct to his master's face.

Closely allied to charges of madness are claims of speakers talking nonsense,

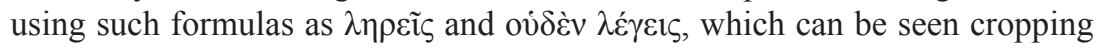
up from time to time in the same passages that I am considering, usually in response to a specific utterance rather than assaulting a grand plan, but the same underlying idea of madness is involved. ${ }^{26}$ But it is also the case that these are allegations, not statements of fact. What such allegations show instead is the bafflement, self-delusion, or simple disagreement of the speaker and more often than not the true meaning of the utterance or action that is being challenged is all too evident to the audience. ${ }^{27}$

Although much of the discussion of Wasps has started from the tragic intertexts, these too offer no straightforward guide to interpretation. It is questionable that the pining and self-harming Phaedra or the background of divine punishment really offer good parallels for Philocleon, his exuberant energy, or comic outcome any more than the quixotic Bellerophon or the impious Aeolus are for that of Trygaeus. ${ }^{28} \mathrm{It}$ would seem that Philocleon has rather more in common with another intertextual strand of madness, the raging aristeia of the epic hero. ${ }^{29}$ The ambivalence of heroic madness is perhaps best encapsulated in the figure of Heracles whose career is defined by both grandiose force and tragic delusion (lussa). In Aristophanes, his heroic rage is transferred to more low-rent exploits in hostelries en route to the underworld (561-67). ${ }^{30}$ Nor is Heracles the only glowering epicizing madman in

26. The relationship between (charges of) nonsense and madness is convincingly demonstrated by Kidd (2014) esp. 26-35.

27. Kidd (2014) 161-86 argues that such charges focus on only that part of jokes that do not make sense (or, to put it in a less categorical form, lack plausibility).

28. Although the idea of madness as divine punishment is certainly alluded to elsewhere in Old Comedy: see Thesm. 679-85.

29. For madness in heroic aristeia, see Homer's Iliad 5.185; 6.101; 8.355; 9.238; 15.605; 16.75, $245 ; 21.5$.

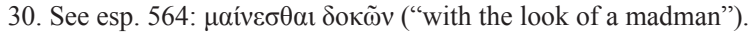


Frogs - that is very much how the chorus characterize Aeschylus at the start of the competition for the chair of poetry in the underworld.

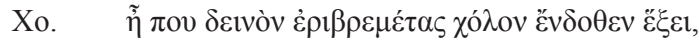

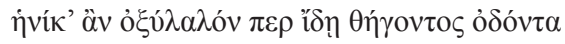

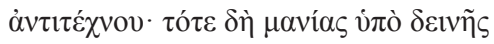

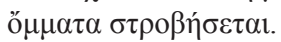

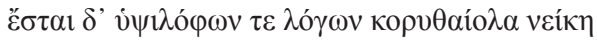

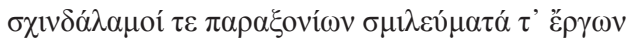

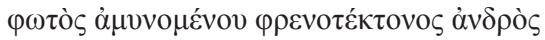

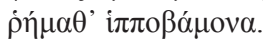

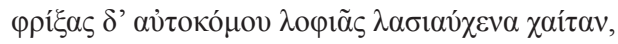

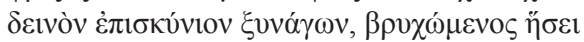

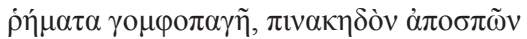

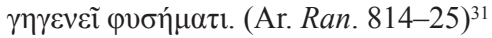

Cho. Thundering mightily, he will have terrible anger within when he sees his opponent sharpening his quick-talking teeth: then with a terrible madness he will roll his eyes.

There will be glittering-helmeted struggles of high-crested words and axle shavings and cutting out of deeds by the man with the craftsman's mind who is defending himself against cavalry-mounted words.

Bristling the shaggy-necked mane of his crest, hair and all, he will frown terribly and roaring he will let fly words that are bolted together, tearing them off like planks in a storm that rises from the bowels of the earth.

Such comic incorporation of epic and tragic models is rarely straightforward, but it is undeniable that the epicizing Aeschylus has a positive role to play in motivating the denouement of Frogs, for all its absurdity. By contrast, perhaps the clearest example of outright negativity in the treatment of divinely inspired vengeance comes in Wealth, with the characterization of Poverty as a Fury (Plut. 423-24). At the opposite pole, the most striking example of Heraclean madness in Wasps is ascribed to Aristophanes himself who sallied forth to slay the monster Cleon with Heraclean anger (orgēe, 1024). ${ }^{32}$

31. Here I am following the order of the paradosis with Henderson (2002) in the Loeb edition against the reordering favored by Wilson (2007).

32. Thus, although the young, fogeyish Bdelycleon is often likened by critics to the presentation of the poet, in this central element the poet has more in common with Philocleon. 
The ambivalence of divine inspiration is never so evident as in its associations

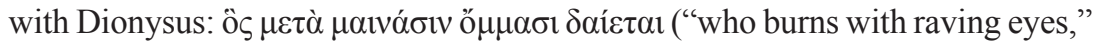
Lys. 1284). While such madness can tip over into violence, with negative, or at least harmful, connotations, as in the Bacchae, the continuum of Dionysiac madness includes such elements as illusion, intoxication, and inspiration, all of which are central to poetry and drama, and which are figured in much more positive terms. ${ }^{33}$ The alcoholic basis of poetic inspiration seems to have been an element of Cratinus's rhetoric of alcoholism in Pytine, probably in turn drawing on Archilochus, in whom Cratinus was clearly interested, who had earlier used that idea (fr. 120W). Aristophanes himself drew on the idea of wine as inspiration in Knights, where the central plot derives from such a recourse, with arguably a strong metapoetic dimension. ${ }^{34}$ Furthermore, in Wasps, Xanthias attributes his dream of Cleon at the assembly to a similar source of inspiration. ${ }^{35}$ In addition to the inspirational qualities of Dionysiac madness, Aristophanes also uses madness to characterize spectating and listening. Thus Dionysus describes his own enthusiasm for Euripides as a form of madness ( $\mu \alpha \dot{\lambda} \lambda \lambda \dot{\alpha} \pi \lambda \varepsilon \tilde{\imath} v$ ì $\mu \alpha i ́ v o \mu \alpha 1$, "I'm more than mad for it," Ran. 124), to Heracles's frank incredulity. ${ }^{36} \mathrm{He}$ 's not the only enthusiastic spectator, though: Pluto's servant is as much an enthusiast for listening at keyholes as Dionysus is for logic-chopping sophistry, and perhaps reflecting on it. ${ }^{37} \mathrm{~A}$ contested form of spectating is similarly a crucial part of Philocleon's addiction to the law-courts, as he articulates it. ${ }^{38}$

As far as the production of tragedy is concerned, and the madness of the individual poet, the monstrous inspiration of the grandly heroic Aeschylus is ultimately set against a madness that is imputed to the logic-chopping Euripides:

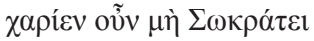
$\pi \alpha \rho \alpha \kappa \alpha \theta \dot{\mu} \mu \varepsilon v$ ov $\lambda \alpha \lambda \varepsilon \varepsilon \bar{v}$,

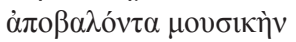

33. See especially Vernant and Vidal-Naquet (1988) 402-9. For Dionysus and Old Comedy, see especially Lada-Richards (1998).

34. So Ruffell (2002) 148-50.

35. In response to his colleague's query whether he is "mad or acting the Corybant" ( $\dot{\alpha} \lambda \lambda$, $\tilde{\eta}$

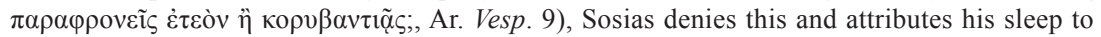
Sabazius; Xanthias then acknowledges the same source and as the basis for the dream (10-11). For Sabazius's association with alcohol, compare Lysistrata 387-98 (along with Adonis); for an association with Dionysus, see Henderson (1987a) on Lysistrata 388 with further references.

36. For Frogs and fandom, see Rosen (2006).

37. The slave uses exactly the same form of words (751) as Dionysus does to express his enjoyment.

38. Wasps 552-75. For Philocleon as spectator, see especially Slater (2002) 86-114, esp. 92-93. 


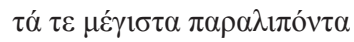

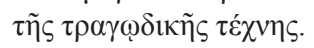

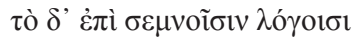

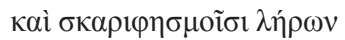

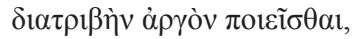

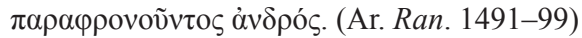

So it is pleasant not to sit by Socrates

babbling,

chucking out musical skill,

and bypassing the greatest part of tragic craft.

Pretentious utterances

and sketchy nonsense

and lazy time-wasting

are the mark of a man who's off his head.

This passage backs carefully away from Dionysus's earlier preference for Euripides. Madness is now reserved, in an abusive sense, for the object of that preference, to whom are now attached the qualities of the second-rate post-Euripidean tragedians that Dionysus had earlier deprecated (92-97). As in other aspects of the final decision in favor of Aeschylus, it is far from clear that this explanation really does away with the heavy-handed characterization of the earlier poet as heroically mad - or perhaps better (and more relevantly for Wasps) whether this second, narrow, ascription of madness dissolves either Dionysus's positive fandom or the ambivalence of the representation of Aeschylus. That latter portrait is equally with the authority of the comic chorus. However that should be estimated in general, ${ }^{39}$ it seems not to have a single notion of tragic madness. Indeed, there are ultimately three modes of tragic madness on display in Frogs - the grandiose heroic posturing, the babbling nonsense, and Dionysiac inspiration and enthusiasm - all challenged and none wholly endorsed.

Thus, where individuals are concerned, and above all the central characters, madness (or allegations thereof) is considerably more nuanced in Old Comedy than it is, for example, in oratory. Where allegations of madness do not prove

39. It is certainly not negligible, and the chorus of Frogs is one of the most universal of all comic choruses, which are commonly more sectional in nature. Dramatically, however, comic choruses are not necessarily definitive at all moments. For further discussion, see Ruffell (2011) 297-302. Discussion of the role of the chorus as an internal audience has been more explicit, albeit contested, in discussions of tragedy: see Gould (1996); Goldhill (1996); Silk (1998); Mastronarde (1999); Foley (2003). 
ultimately unfounded or belied by success, they are usually highly ambivalent. Such personalized madness is not, however, the only way that madness is invoked in Old Comedy. As in oratory, madness can also be used of political, cultural or social circumstances that are being critiqued or rejected. Thus in Lysistrata, the madness of constant war is the subject of both the female chorus and, extensively, in Lysistrata's confrontation with the proboulos. The female semi-chorus use the language of madness of the male semi-chorus (336) and their intentions to burn out Lysistrata and the other women who have seized the Acropolis, but the same song ends with a prayer that the women "rescue

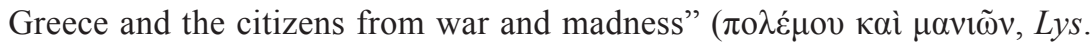
342). The gendered nature of this madness - war, in a quasi-hendiadys, and the politics that surrounds it - and of the critique that is offered only grows stronger as Lysistrata takes on the Proboulos. This is at its most explicit in her sarcastic commentary on the insanity of men walking around the market stalls in full military drag, which the Proboulos defends as something that manly men ( $\tau$ où $\grave{\alpha} v \delta \rho \varepsilon i ́ o v \varsigma)$ do:

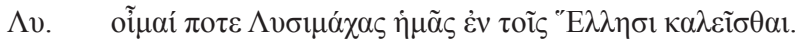

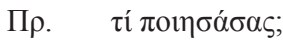

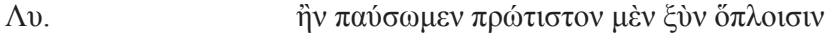

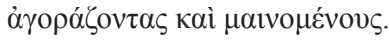

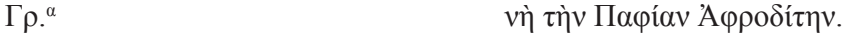

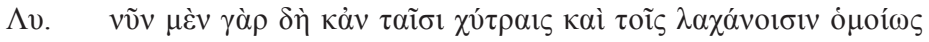

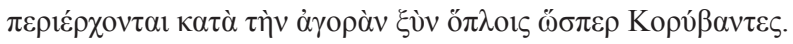

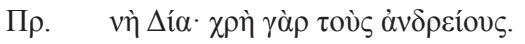

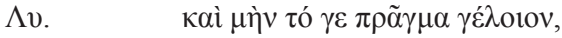

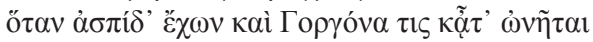
коракívous. (Ar. Lys. 554-61)

Lys. I think that one day we will be called Lysimaches in Greece.

Pr. By doing what?

Lys. First of all, if we stop men going to the market in armor like crazies.

Wo. ${ }^{1} \quad$ Yes by Paphian Aphrodite.

Lys. For at the moment even among the pot and veg stalls they go around the market fully armed, like Corybantes.

Pr. Yes by Zeus: that's what real men do.

Lys. It's a ridiculous act when someone with a Gorgon-shield buys sardines.

Here madness is clearly parsed by Lysistrata as absurdity and (here) something 
to be laughed at ( $\gamma \varepsilon \dot{\delta} \lambda$ otov). ${ }^{40}$ Such an association of warfare and the politics of war with madness is something that anticipates - and is perhaps picked up by-Isocrates. ${ }^{41}$

But comedy's critique of cultural madness extends more widely. Even more strongly gendered and very striking, but less explicitly central to the main plot-line, is the critique of Athenian social norms by the chorus of Thesmophoriazusae:

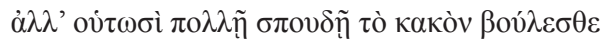

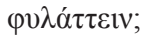

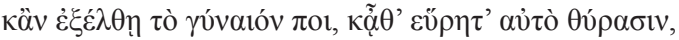

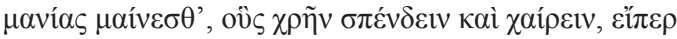

$\dot{\alpha} \lambda \eta \theta \tilde{\omega} \varsigma$

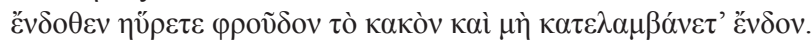

(Ar. Thesm. 791-94)

but do you want to guard the monster with such zeal?

And if the female goes out anywhere, and then you find it out of doors

you rave with madness, who should be pouring libations and celebrating, if you really

had found the monster had left the house and you weren't keeping it indoors.

Male responses to transgressions of the ideology of seclusion are parsed as irrational - and by extension the underlying nature of Greek (and especially Athenian) misogyny.

To be sure, not all such instances of cultural madness are gendered in that way, as a female critique of patriarchy - Chremylus's attack on poverty in Wealth (noted above, p. 337; and see also 500-4) is not (indeed it is an attack on a female personification) - but the pairing of Lysistrata and Thesmophoriazusae in this respect, and without much effective or explicit countering, is certainly striking. This phenomenon may be set against another observation, that in plays that feature a female protagonist, direct rhetorical challenges to her plans in terms of madness do not occur. Particularly where women are prime movers in the plot, then, there seems to be a marked distinction between the transgressive women of tragedy and the transgressive women of comedy, which works to the latter's advantage. ${ }^{42}$ One explanation for this may be that such a direct challenge might

40. For madness to be the target of mockery (specifically skōptein), see also Clouds 350 .

41. See n. 16, above.

42. Thus although Lysistrata invokes a different and very specific kind of tragic model in the shape of Melanippe (1124), there are already marked differences from those such as Phaedra. 
be too destabilizing to the plan articulated by the female protagonists. Another is that it may be a by-product of the social reticence around women, including a reluctance to address or even name citizen wives, which carries over from the Athenian social context into comedy. ${ }^{43}$ But it may also be about protecting the male audience's sensibilities and circumscribing the degree of transgression that the innovation of female comic protagonists presented. Given how common it is to accuse male peers of madness within Athenian political discourse, admission of female characters to that degree of political intimacy may have been a step too far (for male characters or playwrights or audiences). Nor indeed do adult women accuse individuals of madness: the only exception is when Praxagora is specifically imitating a male speaker. ${ }^{44}$

Thus there is an ambivalence in the rhetoric of madness in Old Comedy. It draws on a broader political discourse of madness as stock-in-trade of public political exchanges, but when used of comic protagonists the assertions of madness, however plausible at first sight, frequently (even normally) turn out to be unsustainable. Yet protagonists (and other characters) may themselves be reacting against a social, cultural or political context that is insane, and where an effective counter is lacking. Charges of personal madness proliferate where the arguments in comedy are particularly problematic or finely balanced. In such circumstances, one finds, as in Frogs that the language of madness explodes, and there is charge and counter-charge, or example and counter-example.

The balance is arguably even finer where sources of authority such as gods or choruses (however compromised or ambivalent) are lacking, silent or reduced. Thus in Ecclesiazusae the charge of madness and nonsense between the first crone and the young man who owes them his body under the new regime reinforce the different sets of norms, values and authority with which the two are operating, without any obvious endorsement from a third party. The young man's response to the new realities is to suggest that the woman is $\operatorname{mad}(\pi \alpha \rho \alpha \varphi \rho \circ \varepsilon \varepsilon i \bar{\zeta}$,

43. For reticence about Athenian women and its influence on comedy, see esp. Dover (1974) 98, 207-12; Schaps (1977); Sommerstein (1980); Henderson (1987b) 106-7. For the development of women as protagonists in comedy, see Henderson (2000).

44. Eccl. 250, noted above, p. 333. In Lysistrata, the proboulos assumes that the women's disorder is ritual in character, and cites the ecstatic rites of Sabazius and Adonis, and gives examples as counterpoint to male political activity (387-98). Even so, their disorder is characterized as tryphe (wanton luxury), not madness. He certainly does not engage with the women on the terrain of political madness. The same is true when Lysistrata taunts him about the women's more heroically irrational khole (464-66). The men consistently prefer terms such as anaideia (shamelessness), hybris (outrageousness) or lalia (babbling) to characterize the women's political intervention, the latter closest to madness. 
Eccl. 1000), which is understandable from the point of view of conventional morality and sexual norms, but literally incorrect given that woman is merely putting into practice what the community has decided. The reverse is true of her charge that the young man is talking nonsense ( $\lambda \eta \rho \varepsilon \tilde{\imath} \varsigma, E c c l .1001)$. It is the last word, but is no resolution.

This ambivalent conflict of madnesses is, I think, strongest in a play that I have only touched on briefly so far, Clouds, where the question of who is mad is as much at stake as the question of who is really clever (dexios) or wise (sophos). Also at stake is the relationship between those categories. Particularly evident here is that - as in the challenges to the plans of protagonists - the charge of madness says as much about the misapprehensions of the challenger as the inadequacies of the challenged. Thus Strepsiades's well-known chicken problem (persisting with the ambiguously gendered alektryōn in the teeth of Socrates's introduction of a gendered alektryaina, 660-63) says as much about his inability to grasp the point as it does about the Prodican pedantry of Socrates. Strepsiades's ascription

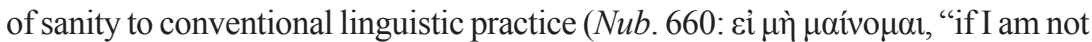
mad") allows Socrates to turn his language against him and suggest that ambiguous (linguistic) gender is a mark of insanity (Nub. 662: ópã $\varsigma \alpha \hat{\alpha} \pi \alpha ́ \sigma \chi \varepsilon 1 \zeta$; "Do you see how you are afflicted?"). The collision between logic and psychological reason powers the immediate joke but it is also a persistent theme, problem and running joke in the play, which both takes off from and constantly returns to Strepsiades's problems in grasping Socrates's doctrines.

Thus the contest between the Weaker and Stronger Arguments, which is the ideological and moral center of the play, is repeatedly set up in terms of the dialogue between madness and cleverness. First, Strepsiades tries to persuade Pheidippides to attend Socrates's thinking-shop in his stead, and misguidedly illustrates his speech with garbled versions of (the comic) Socrates's doctrines. Pheidippides splendidly denounces the madness of both the school and his impressionable and stupid father:

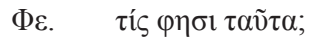

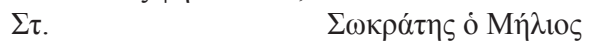

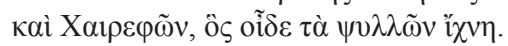

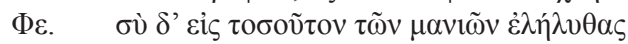

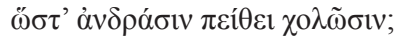

$$
\begin{aligned}
& \Sigma \tau . \quad \quad \varepsilon \dot{\sigma} \quad \text { có } \mu \varepsilon 1
\end{aligned}
$$

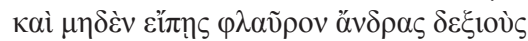

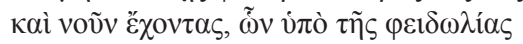

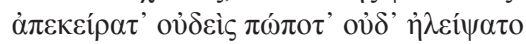

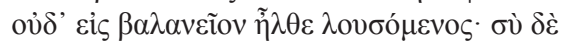




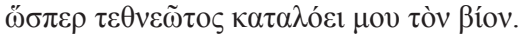

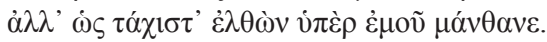

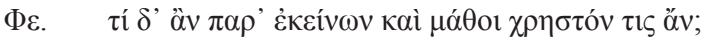

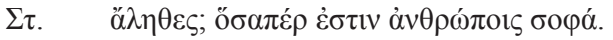

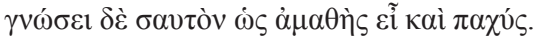

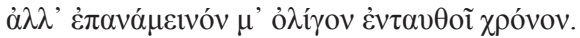

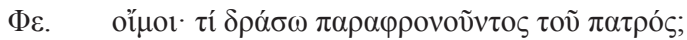

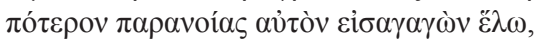

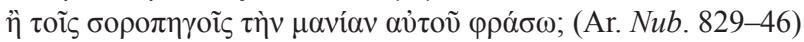 \\ Ph. Who says these things? \\ Str. Socrates the Melian, \\ and Chaerephon, who knows the tracks of fleas. \\ $\mathrm{Ph}$. Have you reached such a pitch of insanity \\ that you listen to madmen? \\ Str. \\ Clean your mouth. \\ and don't say anything silly about clever \\ and intelligent men. Their thrift means none of them ever \\ cut their hair or used oil \\ or went to the baths to wash. You \\ are washing away my life as if I were a dead man. \\ Right: quick as you can, go and learn for me. \\ $\mathrm{Ph}$. What good would anyone ever learn from those men? \\ Str. Really? These men own whatever that's clever. \\ You will recognise that you are stupid and thick. \\ Just wait here for me for a little while. \\ $\mathrm{Ph}$ Oh no! What am I going to do when my father is off his head? \\ Should I ask a court to declare him insane \\ or speak of his madness to the coffin-makers?
}

Pheidippides deploys a veritable barrage of the varied lexicon of madness to describe the school and its hapless victim: $\mu \alpha v i ́ \alpha, \chi 0 \lambda \tilde{\alpha} v, \pi \alpha \rho \alpha \varphi \rho o v \varepsilon \tilde{v}$, and $\pi \alpha \rho \alpha ́ v o 1 \alpha$. In targeting both, Pheidippides is reinforcing the mutual accusations of madness of the earlier scene. Father and son also engage in mutual allegations of stupidity and widely divergent views about the intelligence of Socrates and his associates, and of its utility. But while Pheidippides is apparently on fertile ground with both his father's stupidity and Socrates's triviality (not to mention personal hygiene), the reminder of his father's intellectual weakness also recalls Socrates's own criticism of Strepsiades. Moreover, Pheidippides himself is deeply compromised, as his father reminds him.

All the same, Pheidippides is persuaded into attending Socrates's establishment. When the arguments are introduced on stage, the juxtaposition of mad- 
ness and cleverness is again set out as the terrain of the debate. Accusations of madness fly between the two Arguments, the one using it to label the Weaker's (a)moral stance, the other to label the Stronger's intellectual incoherence (925-26, with 932). Given the outcome of the contest and its aftermath, both positions and that juxtaposition itself seem to be reinforced, as the Stronger Argument is unable to sustain his intellectual position and caves in, while the Weaker Argument's regime leads to father-beating and ultimately a ticking-off from the Clouds.

For when the compromised Pheidippides returns from the thinking-shop, his language of madness has shifted, as has the nature of his moral deficiencies. Now he articulates theological-physical doctrines that echo Strepsiades's own garbled version of Whirl (Dinos) replacing Zeus, and his charge of nonsense is targeted at Strepsiades who has turned against them and laments his own earlier madness (1469-75). Both father and son, then, focus attention on Strepsiades's credulity and stupidity, but attention is also drawn to Pheidippides's new rhetoric of madness and cleverness. Unlike the father, the suggestion is not that the son shares an inability to grasp the finer points of the school's wacky materialism, but rather that he is using his father's own garbled version for tactical advantage, and thereby displays intellectual dishonesty to match his father's financial dishonesty and stupidity. The language of madness questions the intellectual and moral coherence of Strepsiades, Socrates and Pheidippides, and it is very hard to see where any of those judgments do not apply. At the same time, those are, in the main, relative rather than absolute judgments that force an audience to re-evaluate one character (or group of characters) in relation to another. They are also allegations made by those same parties who are themselves compromised..$^{45}$ The question thus remains, just as in Wasps, as to where sanity really does lie.

\section{Madness and Civilization}

To conclude this paper, I turn back to Wasps and consider the play again in the light of this complex use of madness in Aristophanes, where claims of madness are rarely straightforward or endorsed or borne out by the fictional events, or where they can be positive expressions, can draw on positive intertexts or be contested. ${ }^{46}$ It is also clear that charges of madness may say more about

45. As this is the revised version of the play, there is a question of how far this madness theme pre- or post-dated Wasps; given what we know of the revision (Dover [1968] lxxx-xcviii) it is unlikely that it all comes from the revision.

46. Although a number of the plays considered above post-date Wasps, I am claiming that the range of connotations was already available to the audience in processing the play. Or, indeed, that later practice may offer some insight as to how Wasps functioned. 
the befuddlement of the one making the charge than the one about whom it is made. Finally, allegations of madness, or an eccentricity that proves not entirely insane anyway, can draw attention to a disturbed social, cultural or political situation as much as a disturbed individual. All of these factors, I suggest, are in play in Wasps.

Accounts of Wasps frequently overlook just what a devious crook Bdelycleon is, and also underplay how autonomous Philocleon and his peers are from the politicians they supposedly cherish. Something of a gap between the two is implied in a curious observation the chorus make on hearing of Bdelycleon's plans for his father: they call him a DemologoCleon (343), and whatever the precise meaning of that ("one who speaks to the people like a Cleon"?) it implies some kind of parallel between the two youngish men as political players, even if they seem to disagree in terms of policy and some kinds of practice. This is particularly odd, given that Bdelycleon's ostensible plan, to which the chorus are specifically responding here, is to take Philocleon out of the political fray to a life of domestic comfort. But it also suggests that the chorus are not as wedded, ideologically or personally, to the figure of Cleon as has been suggested.

Equally curious is the metatheatrical aporia expressed by Bdelycleon when he articulates his plan for turning the whole city into an imperially-funded oikos:

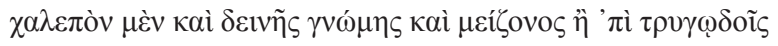

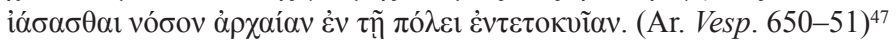

It's difficult and fiendish and more than comic poets can do to heal an ancient sickness innate to the city.

Of course the obvious referent is Philocleon's jury-madness, but the description of the disease as "innate and ancient" suggests something much more fundamental than a keenness to sit on juries, something at the level of the character of the city or citizens. And indeed the imaginary future sketched by Bdelycleon would fundamentally alter the character of the city from one of active, politically engaged citizens to one of passive consumers of pleasures obtained by imperial tribute (698-712).

Philocleon's defense of his desire to go to court has sketched this fundamental character against which Bdelycleon is reacting. His passion actually is not for jury service per se, but a desire for entertainment, control and a passionate desire to convict. Bdelycleon's argument, such as it is, is that the apparent control is illusory. Philocleon's default assumption is that everyone presented before him

47. Wilson's adoption of $\dot{\varepsilon} v \tau \varepsilon \tau \alpha \kappa \nu i ̃ \alpha v$ here significantly undermines the force of the line. I prefer

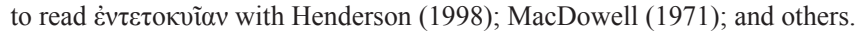


(particularly the elite) is guilty and is trying to hoodwink the jurors (much as they may enjoy it). All of these propositions are tested in the trial at home.

Thus the playing out of a courtroom drama at home, although ostensibly to allow Philocleon to exercise his jury mania in comfort, turns out in fact to be an attempt to exert control over the juror and thereby contrive to pervert the course of justice. It demonstrates the stubborn resistance of the juror and what it takes to overwhelm him - and with what consequences. All of this becomes, as I noted above, focused on and through Philocleon's character, and just as the trial clearly allegorizes Athenian political practice it also allegorizes Athenian political character.

As is often noted, the trial of the dog echoes allegorically the trial to which the chorus and Philocleon were intending to go. But it is absolutely crucial that the dog, Labes, who evokes the general Laches, is quite plainly guilty as charged (836-38). The name itself, Thief (Labes < lambano, "I take"), reinforces the point in case any audience-member was in any doubt. The trial is thus set up as an attempt by an elite speaker to have a fellow member of the elite wrongfully acquitted. After running through the repertoire of stunts to get his client off-and Philocleon displays to good effect the ability to participate in the performance and remain committed to his duty to convict-Bdelycleon only secures the conviction, and for the moment breaks his father, by blatantly, and again quite explicitly, cheating (987-92).

If this were really a straightforward critique of populist democratic justice, then Aristophanes surely needed a better victim, a better advocate and a juror whose determination to convict was rather more unreasonable than it actually turns out to be. As with other individuals charged with madness in Aristophanes, it would seem that Philocleon's and by extension his fellow Athenians' commitment to judging may be quixotic and unhealthy but nonetheless it is viable, effective and even necessary as well. Conversely, the actions of Bdelycleon, both in the domestic court and in setting it up in the first place as a means to exert elite control over Philocleon, amply demonstrate why the Athenians find it hard to shake the disease, and even perhaps why the disease took hold in the first place. It is no wonder that Bdelycleon finds it hard to heal the disease when he, and those like him, are so closely implicated in it in their own right.

For all that Bdelycleon succeeds in displacing Philocleon from the public political space and from (allegorical) political activity, his domestication, even privatization, of Athenian politics does not fundamentally change its character, or that of his father. The elaboration of the ostensibly private sphere, with its dinner and symposium, sharpens up the class and status divide as Philocleon allows himself to be inducted into the manners appropriate to these social gatherings but proves unable to control his unruly and vulgar nature. Yet this private sphere is 
a curiously populated one. Bdelycleon would have his father socialize with, and his father does eventually socialize with, very serious political players indeed, from a variety of political traditions (1219-22, 1299-1303), and including Cleon himself. But given Philocleon's own class-based analysis of his courtroom actions, Bdelycleon's alliance with Labes and the chorus's observation of some fundamental affinity between Bdelycleon and Cleon, it is not that surprising to see that the presentation of the elite transcends overt political stance. The shift in context from public to private reveals that the play is ultimately about exposing the fault-line between the interests of the ordinary citizen and those of the elite, who are in positions of social power in this sphere. Philocleon is unwilling (or unable) to find an accommodation, to modify his character and behavior on their terms, yet is deprived of his previous means of self-assertion in this new regime. These factors provide one explanation for the manic aporia and undirected exuberance and competition of the conclusion: self-expression closed down to a formal and figural mode, kept at a distance from the politics of the public and private spheres.

\section{Conclusion}

Aristophanes's discourse of madness draws on the use of madness in contemporary political and social discourse, both as a feature of individuals and of groups or societies, but is much more ambivalent where the madness of individual characters is concerned. The use of madness in Wasps needs to be understood in that context. The problem of Philocleon's madness, Bdelycleon's apparent failure to engineer a cure, and its ultimate expression in an apparently inexplicable and unmotivated dance-off require explanation less in terms of why it is a problem and more in terms of why it is necessary or important. Bdelycleon fails because he is perpetuating and indeed seeking to deepen an underlying power imbalance between mass and elite that the activity of Philocleon and his peers in the law-court seeks to counter. Indeed, Bdelycleon would deprive Philocleon both of this means of political selfassertion and the attendant political check on the power of the elite. There is no suggestion that Philocleon's position that the elite are basically crooks is wrong, and the sense of an alignment of elite interests across political boundaries is only reinforced in the sympotic scenes after the parabasis. Persisting in trying to judge and to convict in these circumstances is both mad and heroic: the innate madness of the Athenian juror. Or perhaps to put it another way, if the system is really stacked against you like this, madness might be the only rational response. ${ }^{48}$ 


\section{Works Cited}

Bakola, E. 2008. "The Drunk, the Reformer and the Teacher: Agonistic Poetics and the Construction of Persona in the Comic Poets of the Fifth Century." CCJ 54: 1-29.

- 2010. Cratinus and the Art of Comedy. Oxford: Oxford University Press.

Barrett, W. S., ed. 1964. Euripides, Hippolytos. Oxford: Clarendon Press.

Biles, Z. P. 2002. "Intertextual Biography in the Rivalry of Cratinus and Aristophanes." AJPh 123.2: 169-204.

- 2011. Aristophanes and the Poetics of Competition. Cambridge: Cambridge University Press.

Butcher, S. H., ed. 1903-31. Demosthenis orationes. Oxford: Clarendon Press.

de Ste. Croix, G. E. M. 1972. The Origins of the Peloponnesian War. London: Duckworth. Dover, K. J., ed. 1968. Aristophanes: Clouds. Oxford: Clarendon Press. well.

Foley, H. P. 2003. "Choral Identity in Greek Tragedy." CPh 98.1: 1-30.

Goldhill, S. 1996. "Collectivity and Otherness - the Authority of the Tragic Chorus: Response to Gould." In Silk 1996: 244-56.

Gould, J. 1996. “Tragedy and Collective Experience.” In Silk 1996: 217-43.

Harvey, F. D. 1971. "Sick Humour: Aristophanic Parody of a Euripidean Motif?" Mnemosyne 24: 362-65.

Henderson, J., ed. 1987a. Aristophanes: Lysistrata. Oxford: Clarendon Press.

—. 1987b. "Older Women in Attic Old Comedy." TAPhA 117: 105-29.

— ed. and trans. 1998-2008. Aristophanes, vols. 1-4. Cambridge, MA: Harvard University Press.

- 2000. "Pherekrates and the Women of Old Comedy." In Wilkins and Harvey 2000: $135-50$.

Hodges, M., dir. 1980. Flash Gordon. EMI/Universal.

Kidd, S. E. 2014. Nonsense and Meaning in Ancient Greek Comedy. Cambridge: Cambridge University Press.

Lada-Richards, I. 1998. Initiating Dionysus: Ritual and Theatre in Aristophanes 'Frogs. Oxford: Clarendon Press.

Luppe, W. 2000. "The Rivalry between Aristophanes and Cratinus." In Wilkins and Harvey 2000: 15-20.

MacDowell, D. M. 1971. Aristophanes: Wasps. Oxford: Clarendon Press.

Mastronarde, D. J. 1999. "Knowledge and Authority in the Choral Voice of Euripidean Tragedy." SyllClass 10: 87-104.

Rosen, R. M. 2000. "Cratinus' Pytine and the Construction of the Comic Self." In Wilkins and Harvey 2000: 23-39.

- 2006. "Aristophanes, Fandom and the Classicizing of Greek Tragedy." In L. Kozak and J. Rich, eds., Playing Around Aristophanes, 27-47. Oxford: Aris \& Phillips.

Ruffell, I. A. 2002. "A Total Write-Off: Aristophanes, Cratinus and the Rhetoric of Comic Competition.” CQ 52.1: 138-63. 
2011. Politics and Anti-Realism in Athenian Old Comedy: The Art of the Impossible, Oxford: Oxford University Press.

Schaps, D. 1977. "The Woman Least Mentioned: Etiquette and Women's Names." CQ 27: 323-30.

Sidwell, K. 1990. "Was Philocleon Cured? The Nosos Theme in Aristophanes' Wasps." C\&M 41: 9-31.

Silk, M. S. 1987. "Pathos in Aristophanes." BICS 34: 78-111.

, ed. 1996. Tragedy and the Tragic: Greek Theatre and Beyond. Oxford: Clarendon Press.

1998. "Style, Voice and Authority in the Choruses of Greek Drama." In P.

Riemer and B. Zimmermann, eds., Der Chor im antiken und modernen Drama, 1-26. Stuttgart: M\&P.

Slater, N. W. 2002. Spectator Politics: Metatheatre and Performance in Aristophanes. Philadelphia: University of Pennsylvania Press.

Sommerstein, A. H. 1980. "The Naming of Women in Greek and Roman Comedy." QS 11: 393-418.

Vaio, J. 1971. "Aristophanes' Wasps: the Relevance of the Final Scenes.” GRBS 12.3: 335-51.

Vernant, J.-P, and Vidal-Naquet, P. 1988. Myth and Tragedy in Ancient Greece, trans. J. Lloyd. New York: Zone Books.

Wilkins, J. and Harvey, F. D., eds. 2000. The Rivals of Aristophanes: Studies in Athenian Old Comedy. London: Duckworth/Classical Press of Wales.

Wilson, N. G., ed. 2007. Aristophanis fabulae. Oxford: Clarendon Press.

Wright, M. E. 2013 "Comedy versus Tragedy in Wasps.” In E. Bakola, L. Prauscello and M. Telò, eds., Greek Comedy and the Discourse of Genres, 205-25. Cambridge: Cambridge University Press. 